\title{
Genetic Differentiation of the Gobies Gymnogobius castaneus and G. taranetzi in the Region Surrounding the Sea of Japan as Inferred from a Mitochondrial Gene Genealogy
}

\author{
Teiji Sota $^{1, *}$, Takahiko Mukai ${ }^{2}$, Toshihiko Shinozaki ${ }^{3, \dagger}$, Hitoshi Sato $^{4}$ \\ and Ken'ichiro Yodoe ${ }^{5, \ddagger}$ \\ ${ }^{1}$ Department of Zoology, Graduate School of Science, Kyoto University, Sakyo, Kyoto 606-8502, Japan \\ ${ }^{2}$ Faculty of Regional Studies, Gifu University, 1-1 Yanagido, Gifu 501-1193, Japan \\ ${ }^{3}$ Graduate School of Fisheries Sciences, Hokkaido University, Minatomachi \\ 3-1-1, Hakodate 041-8611, Japan \\ ${ }^{4}$ Shimane Wildlife Survey, 141 Maki, Izumo 693-0121, Japan \\ ${ }^{5}$ Hoshizaki Green Foundation and Shinjiko Nature Museum \\ "Gobius", Hirata 691-0076, Japan
}

\begin{abstract}
The phylogenetic relationships between gobies of the genus Gymnogobius were analyzed using mitochondrial cytochrome $b$ gene sequences, focusing on the species currently classified as $G$. taranetzi and G. castaneus that occur in Japan, South Korea, and Russia. Gobies of the two species collected at 12 localities in Japan, South Korea, and Russia formed a monophyletic clade (called the "castaneus species complex" here) with $G$. breunigii as the sister clade. Within the species complex, six lineages were recognized: (L1) G. castaneus from the Akigawa River, Tokyo, Japan; (L2) G. castaneus from Yuza, Yamagata, Japan; (L3) G. taranetzi from Russia and South Korea; (L4) G. castaneus from the Tonegawa River, Chiba, Japan; (L5a) G. taranetzi from Shimane, Japan; and (L5b) G. castaneus + G. taranetzi from the Japan Sea coast of northern Japan. The two local lineages of G. castaneus (L1 and L2) are highly divergent from the others. The Japanese populations of $G$. taranetzi have diverged from the continental $G$. taranetzi populations, while one mitochondrial lineage ( $L 5 b)$ is shared with $G$. castaneus of northeast Japan. Therefore, the current species G. taranetzi and G. castaneus as defined morphologically are polyphyletic, necessitating a taxonomic revision. The genetic differentiation of isolated local lineages and the evolution of taranetzi- and castaneus-type gobies have likely occurred repeatedly in brackish/freshwater habitats around the Sea of Japan. We discussed the time of divergence for these gobies based on a tree with the molecular clock assumption.
\end{abstract}

Key words: biogeography, molecular clock, freshwater fish, mitochondrial DNA

\section{INTRODUCTION}

The gobies of the genus Gymnogobius (Pisces: Gobiidae) in East Asia are adapted to shallow marine, brackish, and freshwater habitats and were classified into 13 species in a recent taxonomic review (Stevenson, 2002). There are six freshwater species in this genus; three of these $(G$.

\footnotetext{
* Corresponding author. Phone: +81-75-753-4078; Fax : +81-75-753-4101;

E-mail: sota@terra.zool.kyoto-u.ac.jp

Present address:

† 2-4-6 Seiwadai, Kawai-cho, Kitakatsuragi-gun, Nara 636-0081, Japan

‡ 2-1-7 Hitsugaoka, Matsue 690-0862, Japan
}

opperiens, G. petschiliensis, and G. urotaenia) spend part of their life in marine habitats and do not show any apparent geographical differentiation between Japan and Korea or within these regions (Harada et al., 2002). Of the other three species, G. isaza is endemic to Lake Biwa (Shiga Prefecture, Japan), whereas $G$. castaneus occurs widely in northern Japan (north from the Kanto and Hokuriku Districts of Japan); G. taranetzi occurs along the southern part of the Japan Sea coast from Toyama to Shimane, Japan, and along the coasts of Korea and Russia (Akihito et al., 2002; Stevenson, 2002). The latter three species complete their life cycles in freshwater (Kawanabe et al., 2001). Aizawa et al. (1994) studied the phylogeny of these species based on allozyme polymorphisms and found that $G$. castaneous pop- 
ulations consisted of two highly diverged lineages, one of which included G. tranetzi in Japan (so-called "Shinjikohaze"). Moreover, the divergence between these G. castaneus lineages were as large as that for each of them with G. breuningii (note changes in scientific names; Chaenogobius castaneus, C. sp from L. Shinjiko, and $C$. laevis in Aizawa et al. [1994] are equivalent to Gymnogobius breunigii, G. taranetzi, and G. castaneus, respectively, according to Stevenson, 2002). The existence of the two diverged lineages in $G$. castaneus lineages has been confirmed in an extensive study of allozyme polymorphisms (T. Shinozaki, M. Hatsumi, K. Wakahama, A. Goto, unpublished). However, the phylogenetic relationships among $G$. breunigii, $G$. castaneous and $G$. taranetzi remain to be resolved with samples including continental $G$. taranetzi. In addition, phylogenetic analysis using mitochondrial DNA sequences would be useful to resolve the relationship among the Gymnogobius species in comparison with the previous results from the allozyme data.

In this study, we analyzed partial nucleotide sequences of the mitochondrial cytochrome $b$ gene in $G$. taranetzi from Primorsky, Korea, and Japan, and in some populations of $G$. castaneus in Japan. Our study demonstrates that the mitochondrial gene genealogy of $G$. taranetzi and $G$. castaneus does not reveal reciprocal monophyly; the continental and Japanese populations of $G$. taranetzi do not have a sister relationship; and the Japanese populations currently classified as G. taranetzi and G. castaneus likely consist of several distinct lineages or species.

\section{MATERIALS AND METHODS}

\section{Sampling and DNA sequencing}

The samples used in this study are listed in Table 1. Skeletal muscles were cut from fresh fish or ethanol-fixed specimens and digested in CTAB buffer with proteinase $\mathrm{K}$. Total genomic DNA was extracted using the standard phenol-chloroform method. For PCR amplification of the mitochondrial cytochrome $b$ gene region, the primers L15172 (5'-TGA GGA CAA ATA TCN TTY TGA GG-3') and H15915 (5'-A CCT CCG ATC YCG GAT TAC A AG AC-3') were used (Harada et al., 2002). In direct sequencing with the PCR products, the dye-terminator, cycle-sequencing reaction was performed with an ABI PRISM BigDye Terminator Cycle Sequencing FS Ready Reaction Kit and reaction products were electrophoresed on an ABI 377 sequencer (Applied Biosystems). The 704-bp sequences are deposited in GenBank (accession: AY450363-

Table 1. List of samples used for the analysis of mitochondrial DNA sequences.

\begin{tabular}{|c|c|c|}
\hline $\begin{array}{l}\text { Species [Japanese name] } \\
\qquad \text { Locality [locality code for Fig. 1] }\end{array}$ & $\begin{array}{c}\text { No. } \\
\text { sequenced }\end{array}$ & $\begin{array}{c}\text { No. } \\
\text { haplotypes }\end{array}$ \\
\hline \multicolumn{3}{|l|}{ Gymnogobius castaneus (O'Shaughnessy, 1875) [Juzukakehaze] } \\
\hline Yoneshirogawa R., Akita, Japan [C1] & 1 & 1 \\
\hline Fukushimagata, Toyosaka, Niigata, Japan [C2] & 2 & 2 \\
\hline Yuza, Yamagata, Japan [C3] & 3 & 1 \\
\hline Tonegawa R., Noda, Chiba, Japan [C4] & 3 & 2 \\
\hline Akigawa R., Tokyo, Japan [C5] & 3 & 1 \\
\hline \multicolumn{3}{|l|}{ G. taranetzi (Pinchuk, 1978) [Shinjikohaze] } \\
\hline Artemovka R., near Vladivostok, Russia [T1] & 3 & 1 \\
\hline Uljin-gun, Gyeongsangbuk-do, South Korea [T2] & 3 & 1 \\
\hline L. Shinjiko, Shimane, Japan [T3] & 3 & 2 \\
\hline Ohtarai-ike, Masuda, Shimane, Japan [T4] & 4 & 1 \\
\hline Maogawa R., Himi, Toyama, Japan [T5] & 1 & 1 \\
\hline Sugatagawa R., Himi, Toyama, Japan [T6] & 3 & 1 \\
\hline Shokawa R., Shinminato, Toyama, Japan [T7] & 1 & 1 \\
\hline \multicolumn{3}{|l|}{ G. breunigii (Steindachner, 1880) [Biringo] } \\
\hline L. Nakaumi, Shimane, Japan & 3 & 3 \\
\hline Maruyamagawa R., Hyogo, Japan & 3 & 2 \\
\hline \multicolumn{3}{|l|}{ G. heptacanthus (Hilgendorf, 1879) [Nikuhaze] } \\
\hline L. Nakaumi, Shimane, Japan & 3 & 3 \\
\hline \multicolumn{3}{|l|}{ G. petschiliensis (Rendahl, 1924) [Sumi-ukigori] } \\
\hline Sugatagawa R., Himi, Toyama, Japan & 1 & 1 \\
\hline \multicolumn{3}{|l|}{ G. opperiens Stevenson, 2002 [Shima-ukigori] } \\
\hline Sugatagawa R., Himi, Toyama, Japan & 1 & 1 \\
\hline \multicolumn{3}{|l|}{ G. urotaenia (Hilgendorf, 1879) [Ukigori] } \\
\hline Uljin-gun, Gyeongsangnam-do, South Korea & 3 & 3 \\
\hline
\end{tabular}




\section{AY450388; AY461730- AY461731).}

\section{Phylogenetic analysis}

For phylogenetic reconstruction, we used six cytochrome $b$ gene sequences of $G$. urotaenia, G. petschiliensis, $G$. isaza, $G$. opperiens, G. uchidai, and G. macrognathos reported in Harada et al. (2002) in addition to our data. A sequence of Rhinogobius giurinus (Rutter, 1897) was used as the outgroup of Gymnogobius (GenBank accession: AB018997; Kumazawa et al., 1999). We performed equal-weight parsimony analysis using PAUP $^{*}$ version 4.0 b10 (Swofford, 2002) with a heuristic search of 100 random addition analyses with tree bisection-reconnection (TBR) branch swapping (MULTREE option in effect). Support for nodes was assessed using 1,000 bootstrap resamplings and a branch support (Bremer, 1994). TreeRot. v2 (Sorenson, 1999) was used to calculate the branch supports.

\section{Estimation of times of divergence}

To estimate the age of divergence between lineages, we compared maximum likelihood trees with and without the molecular- clock assumption using the likelihood ratio test. The maximum likelihood (ML) analysis used PAUP*, and a tree search was performed using a heuristic search of 10 random addition analyses with TBR branch swapping (MULTREE option in effect). The parameters used in the ML analysis followed the results of the hierarchical likelihood ratio test implemented in Modeltest version 3.06 (Posada and Crandall, 1998). The Tamura and Nei (1993) model with the gamma shape parameter was selected as the fittest model. When the $M L$ trees with and without the molecular clock assumption did not differ, we used the former ultrametric tree to estimate age.

\section{RESULTS}

Partial nucleotide sequences of the mitochondrial cytochrome $b$ gene were determined for 44 specimens (Table 1), and 28 haplotypes were distinguished. A total of 34 haplotypes from 10 species of Gymnogobius, including six haplotypes by Harada et al. (2002), were used in the phylo-

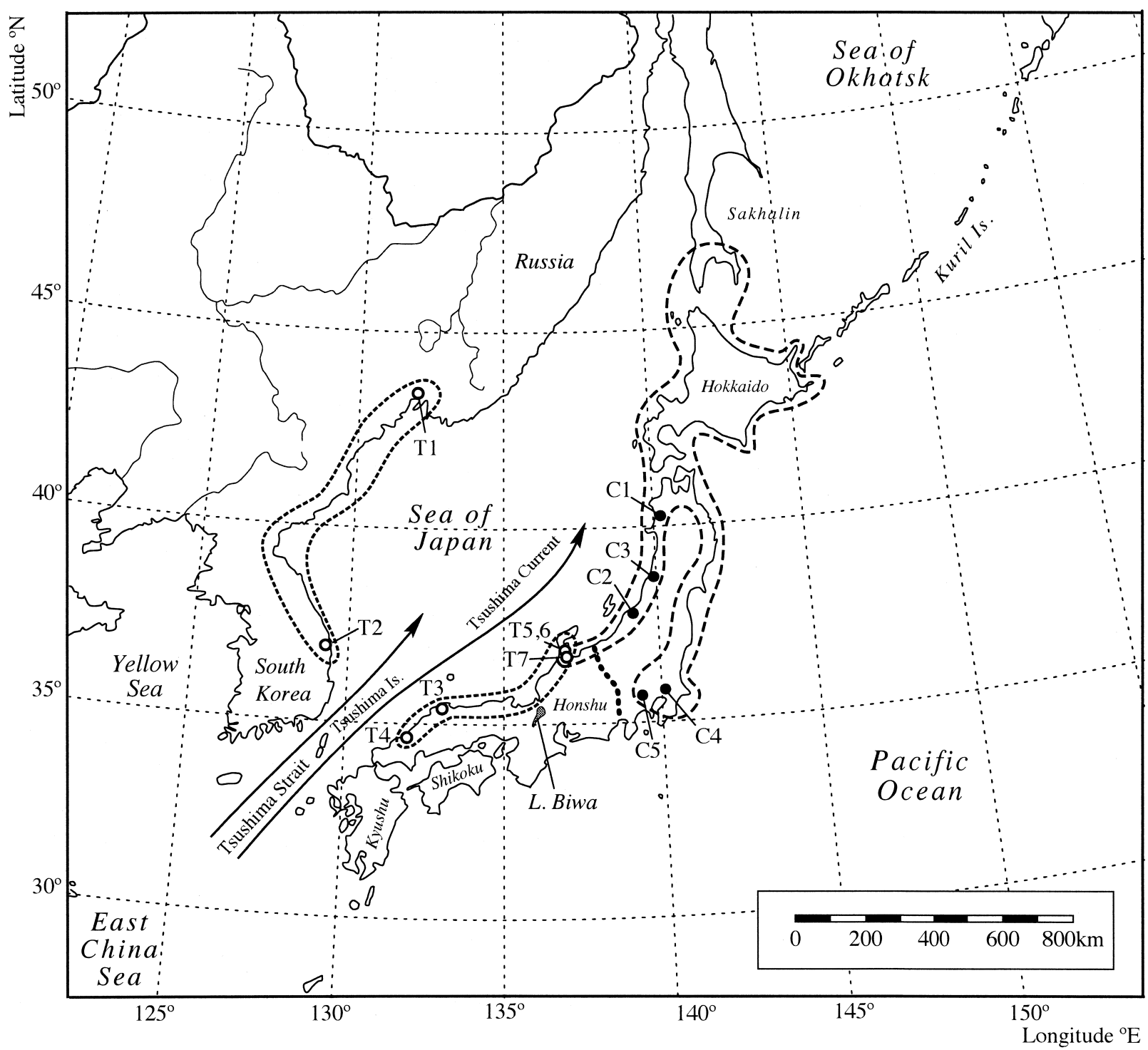

Fig. 1. Map of Japan and Far East, showing sample localities of Gymnogobius castaneus (closed circles) and G. taranetzi (open circles). Broken lines indicate distribution ranges of $G$. castaneus and $G$. taranetzi (Akihito et al., 2002). For locality codes (C1-5; T1-7), see Table 1. The dotted line represents the west margin of Fossa Magna that may correspond to the position of the east channel (see Fig. 3). 
genetic analysis with Rhinogobius giurinus as the outgroup. The maximum parsimony analysis resulted in four shortest trees of 741 steps (consistency index, $\mathrm{Cl}$, excluding uninformative characters $=0.50$; retention index, $\mathrm{Rl}=0.81$; rescaled consistency index, $\mathrm{RC}=0.42$ ). Most of the branches are supported with high bootstrap percentages, but basal relationships of Gymnogobius species were not resolved
(Fig. 2).

The G. castaneus and G. taranetzi sequences formed a monophyletic clade, with $G$. breunigii as the sister clade. The $G$. castaneus and $G$. taranetzi sequences did not reveal reciprocal monophyly. Therefore, we called the monophyletic clade consisting of these two species "the castaneus species complex." In this clade, at least five distinct lineages

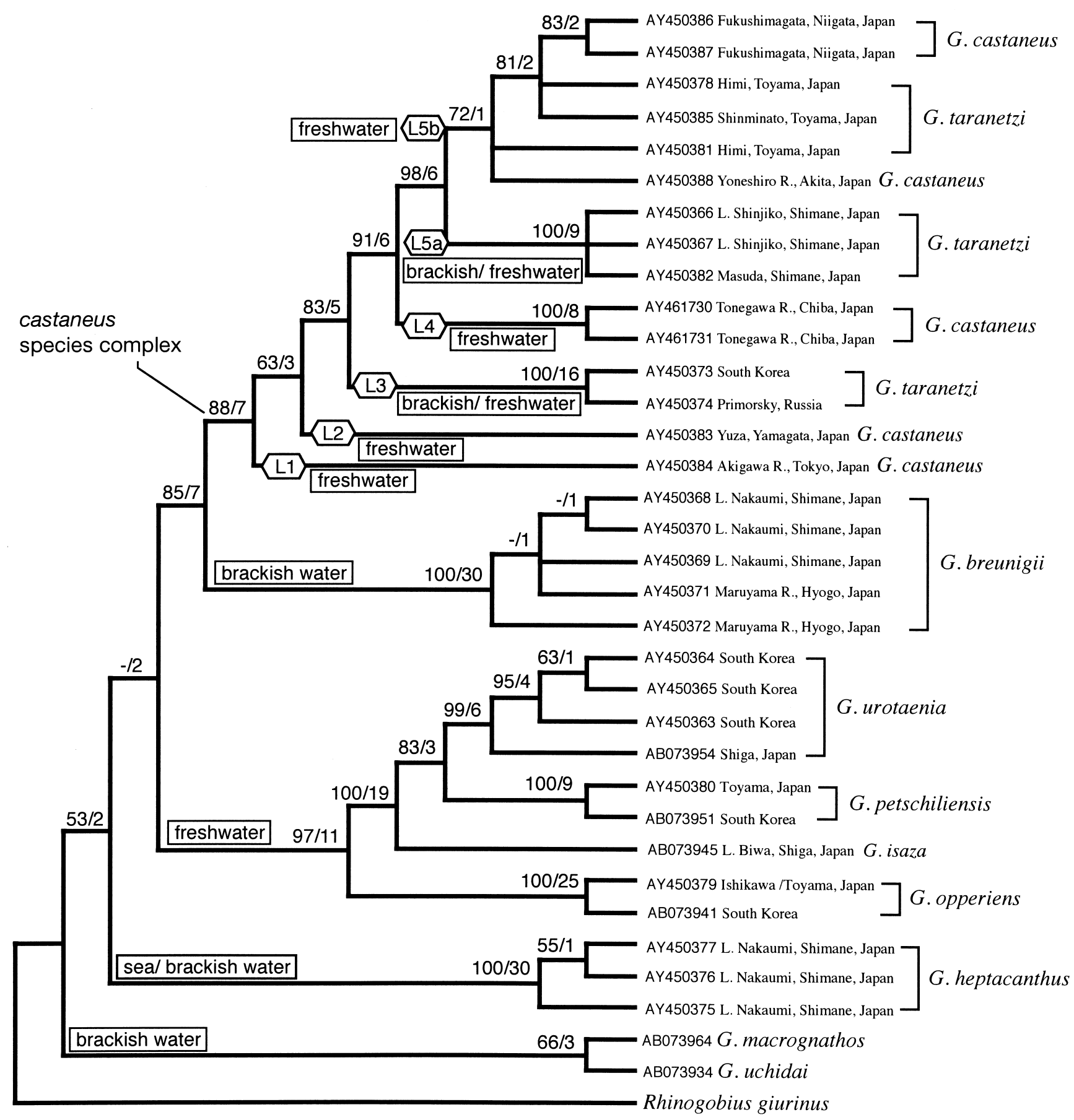

Fig. 2. Strict consensus of four shortest trees resulting from the maximum-parsimony analysis. Bootstrap percentages (when $>50 \%$ ) and branch supports (following "I"; Bremer, 1994) are indicated above the branches. Aquatic habitats (sea, brachkish, and freshwater) are also indicated. GenBank accessions are given at terminals where sequences with AB-numbers are published by Harada et al. (2002) and those with AY-numbers by the present study. 
are recognized: (L1) G. castaneus from the Akigawa River, Tokyo; (L2) G. castaneus from Yuza, Yamagata; (L3) G. taranetzi from Russia and Korea; (L4) G. castaneus from the Tonegawa River, Chiba; and (L5) G. castaneus and G. taranetzi from the Japan Sea coast of Japan. The last lineage is subdivided into ( $L 5 a) G$. taranetzi from Shimane and (L5b) G. castaneus with $G$. taranetzi from the coastal region of northern Japan facing the Sea of Japan.

The likelihood ratio test showed that the ML trees with and without the molecular-clock assumption did not differ significantly $(2 \Delta=2[-4110.5-[-4127.5]]=34.0, \mathrm{df}=34, P$ $>0.1)$. Therefore, we used the ultrametric tree to estimate the age of divergence of the lineages (Fig. 3). The topology of this tree generally coincided with that of the maximum parsimony tree except for the placement of $G$. heptacanthus. To calibrate the ages, we assumed that the node height
(0.047) at the branch between the continental $G$. taranetzi (L3) and the Japanese G. castaneus-taranetzi (L4-L5a-b) lineages corresponds to 3.5 million years ago $(\mathrm{Ma})$, which is when the Tsushima Current began to flow into the Sea of Japan (Tada, 1994). Earlier than 3.5 Ma (beginning at about $10.5 \mathrm{Ma}$ ), the Tsushima Strait was closed and there was a land bridge between southwest Japan and Korea, enabling the possible migration of gobies across the Sea of Japan; more recently than $3.5 \mathrm{Ma}$, migration might have been difficult because of the flow of the Tsushima Current. This calibration resulted in a substitution rate of $2.7 \%$ per million years (My). With this calibration, the differentiation between the castaneus species complex and G. breunigii occurred during the mid Miocene (10 Ma). The differentiation of the two Japanese endemic lineages (L1 and L2-L5) has occurred since the beginning of the Pliocene (6 Ma),

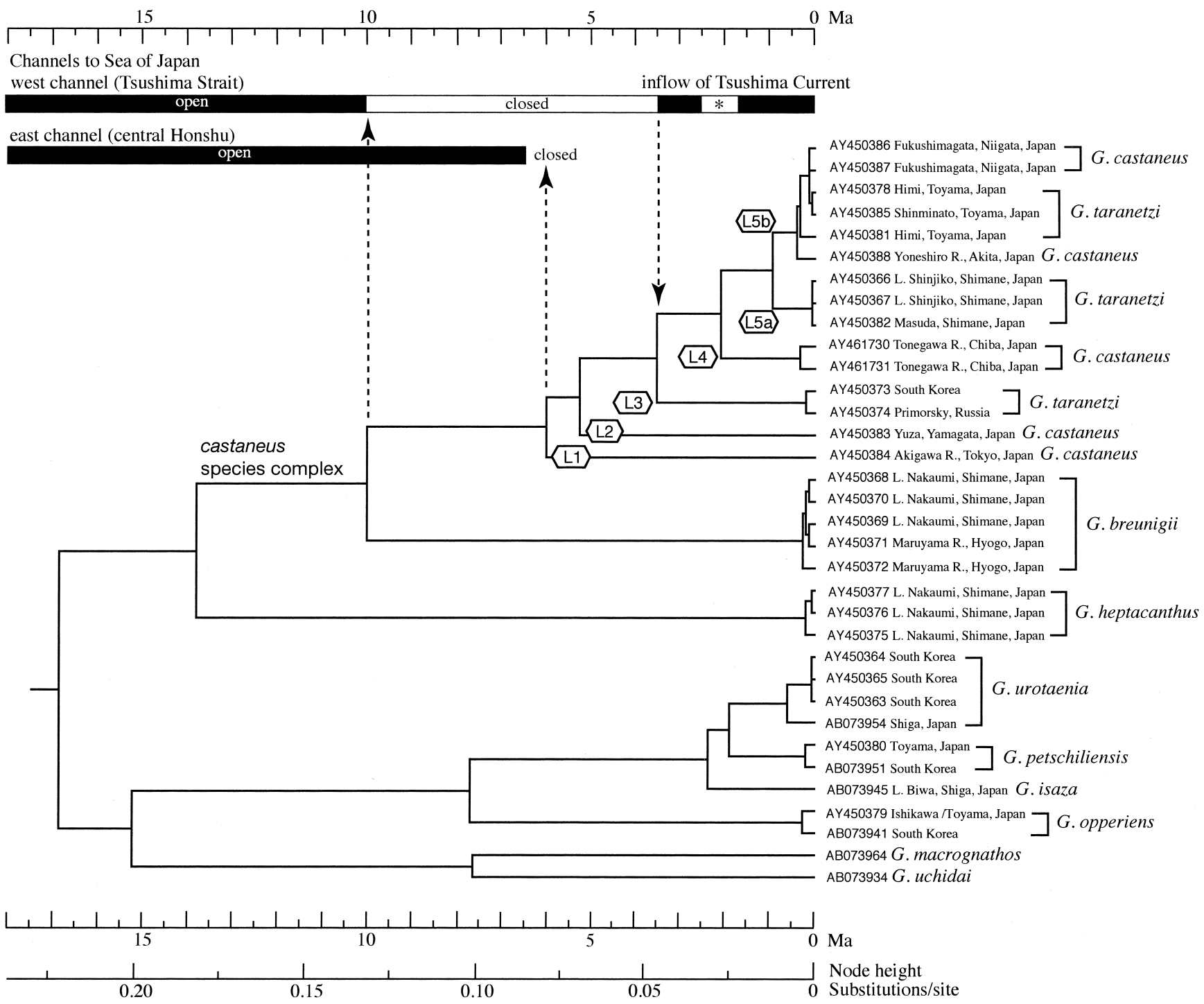

Fig. 3. The maximum likelihood tree with molecular-clock assumption with a calibration of age ( $3.5 \mathrm{Ma})$ at the branching of the continental (L3) and Japanese lineages (L4-5a,b). Open (black bar) and closure (open bar) of the west and east channels to the Sea of Japan followed Tada (1994); the closure in 2.5-1.7 Ma (*) of the west channel followed Kitamura et al. (2001); note that the west channel might be closed repeatedly during glacial periods after $1.7 \mathrm{Ma}$. 
whereas the differentiation of the other Japanese lineages ( $L 4$ and L5a-b) has occurred since the end of the Pliocene (after $2.1 \mathrm{Ma}$ ).

\section{DISCUSSION}

This study revealed that the gobies currently classified as $G$. taranetzi and $G$. castaneus form a monophyletic clade sister to $G$. breunigii in the mitochondrial gene genealogy. However, these gobies, defined here as the "castaneus species complex", consist of divergent mitochondrial lineages (L1-L5) and that the monophyly of each species was not supported. In the mitochondrial gene genealogy (Figs. 2 and 3), two Japanese $G$. castaneus lineages L1 and L2 differentiated the earliest from the rest of the castaneus species complex. The continental $G$. taranetzi (L3) and Japanese $G$. taranetzi + G. castaneus (L4, L5a, L5b) lineages are well differentiated, and gene flow across the Sea of Japan might have been absent for a long time. There is some differentiation among $G$. castaneus from the Tonegawa River in Chiba (L4), G. taranetzi from Shimane (L5a), and G. castaneus with $G$. taranetzi from the Japan Sea coast in the northeastern region (L5b). This divergence represents a more recent geographical differentiation within the lineages of $G$. castaneus and $G$. taranetzi in Japan.

The diagnostic characteristic of $G$. taranetzi and G. castaneus is the presence/absence of oculoscapular canals and pores (Stevenson, 2002), and our species identification relies on this character. However, our mitochondrial gene genealogy suggests that the character state changed repeatedly within the castaneus species complex. Because the oculoscapular canals and pores are present in G. breunigii, a brackish species sister to the castaneus species complex, loss of these canals and pores (i.e., transformation to the $G$. castaneus type) might have occurred repeatedly in the castaneus species complex. Therefore, the previous diagnostic characteristic likely represents homoplasy, and a more detailed morphological analysis is needed to clarify the species status of different populations in the castaneus species complex.

The sharing of a mitochondrial lineage (lineage L5b) between $G$. castaneus and $G$. taranetzi from northeastern Japan was unexpected. This suggests that they are in fact two forms of the same biological species, or that, even if they are separate species, they hybridize at the contact zone and mtDNA might have introgressed between the two species (note that all the specimens of $G$. taranetzi in $\mathrm{L} 5 \mathrm{~b}$ were from the boundary area between the two species; Fig. 1). Further morphological analysis and phylogenetic study using nuclear DNA sequences are necessary. A freshwater fish, the medaka Oryzias latipes, has a contact zone between two genetically divergent forms in the coastal area of the Japan Sea (north of Kyoto and Hyogo Prefecture) (Sakaizumi, 1984). In these freshwater fishes, past geographical isolation and secondary contact between northern and southern populations along the Japan Sea coast might have affected the genetic constitution of local populations.

It is intriguing to explore the time and associated geographical setting for the diversification of Gymnogobius species in the evolutionary study of freshwater fishes in Japan. However, no fossil Gymnogobius is available to identify the past fauna or to calibrate the molecular clock of the mitochondrial genes. In this study, we assumed that the vicariance of the continental and Japanese $G$. taranetzi occurred after 3.5 Ma. This assumption was based on palaeo-oceanographic studies of the Sea of Japan, which indicate that the Tsushima Strait in the southwest of the Sea of Japan (Fig. 1) was closed from 10.5 to $3.5 \mathrm{Ma}$ (Tada, 1994). During this period, dispersal of the castaneus species complex might have been possible between the Korean Peninsula and southwest Japan. Since 3.5 Ma, the Tsushima Current has flowed into the Sea of Japan during the interglacial periods. Therefore, population exchange between the continental and Japanese lineages was likely limited after 3.5 Ma. With our calibration method, 3.5 million years corresponds to $9.4 \%$ sequence difference, giving a molecular clock of $2.7 \%$ per My. This rate is comparable to the previous estimate for Gymnogobius, 2.2-2.4\% per My, by Harada et al. (2002); their estimate was based on the postulation that $G$. isaza, an endemic species in Lake Biwa, originated in ancient Lake Kouga in 2.7-2.5 Ma (Kawabe, 1996) and the range of previously published substitution rates in fish cytochrome $b$, between $0.8 \%$ per My (Cantatore et al., 1994) and $2.8 \%$ per My (Orti et al., 1994). In a palaeo-oceanographic study after Tada (1994), Kitamura et al. (2001) proposed that the Tsushima Strait was closed again from 2.5 to $1.71 \mathrm{Ma}$. If we use $1.71 \mathrm{Ma}$, instead of $3.5 \mathrm{Ma}$, as the time of divergence between the continental and Japanese lineages of the castaneus species complex, the corresponding molecular clock would be unusually fast, $5.5 \%$ per My. Therefore, it would be reasonable to assume that the closure of the strait in 2.51.71 Ma did not facilitate gene flow between the continental and Japanese populations because of its relatively short duration and/or the effect of the glacio-eustatic sea level fluctuation since $2.5 \mathrm{Ma}$.

The estimated times of cladistic events in Gymnogobius coincide with those of some geohistorical events (Fig. 3). The split between $G$. breunigii and the castaneus species complex occurred $10 \mathrm{Ma}$, the time when the Tsushima Strait was once closed in the late Miocene. The split of $L 1$ (G. castaneus from Tokyo) from other populations of the castaneus complex occurred $6 \mathrm{Ma}$, followed by the split of L2 (G. castaneous from Yamagata). In the Late Miocene, the Japanese Islands were extensively uplifted (lijima and Tada, 1990; Yonekura et al., 2001). In central Honshu, the channel between the Pacific Ocean and the Sea of Japan along Fossa Magna was closed by 6 Ma (lijima and Tada, 1990; Tada, 1994; see Fig. 3), and this might result in isolation and differentiation of L1 lineage. Also, in the northern Honshu (Tohoku District), many lake basins appeared following the uplift along the Ohu Backbone Range (lijima and Tada, 1990; Yonekura et al., 2001). This might be related to the 
isolation and differentiation of $\mathrm{L} 2$ lineage.

Our study revealed that the species complex consisting of the nominal species $G$. castaneus and $G$. taranetzi exhibits notable local divergence, as well as incongruence between the morphological species boundary and mitochondrial lineages. A more thorough sampling of local specimens of this species complex is needed to confirm the several different levels of phylogeographic divergence associated with the geohistory of the Sea of Japan and the Japanese Archipelago.

\section{ACKNOWLEDGEMENTS}

We are grateful to Y. A. Tshistjakov and S. Shed'ko at Far East Branch of Russain Academy of Science, S-H. Lee, Director of the Gyeongbuk Research Center for Fresh-water Fish, Korea, O. Inamura, Uozu Aquarium; T. Suzuki, Amagasaki-kita High School; K. Yamaguchi, N. Aoyama, K. Sasaki, T. Kobayashi, G. Yamamoto, H. Nakano, and M. Hayashi at Hoshizaki Green Foundation; and Y. Nagahata for care of specimens. We are much grateful to $K$. Watanabe and anonymous reviewers for useful comments. This study was supported in part by a Grant-in-Aid for the Biodiversity Research of the 21st Century COE (A14).

\section{REFERENCES}

Aizawa T, Hatsumi M, Wakahara K (1994) Systematic study on the Chaenogobius species (Family Gobiidae) by analysis of allozyme polymorphisms. Zool Sci 11: 455-465

Akihito, Sakamoto K, Ikeda Y, Sugiyama K (2002) Gobioidei. In "Fishes of Japan with Pictorial Keys to the Species, English Edn." Ed by T Nakabo, Tokai University Press, Tokyo, pp 1139-1310, 1596-1619

Bremer K (1994) Branch support and tree stability. Cladistics 10: 295-304

Cantatore P, Roberti M, Pesole G, Ludovico A, Milella F, Gadaleta MN, Saccone C (1994) Evolutionary analysis of cytochrome $b$ sequences in some Perciformes: evidence for a slower rate of evolution than in mammals. J Mol Evol 39: 589-597

Harada S, Jeon SR, Kinoshita I, Tanaka M, Nishida M (2002) Phylogenetic relationships of four species of floating gobies (Gymnogobius) as inferred from partial mitochondrial cytochrome $b$ gene sequences. Ichthyol Res 49: 324-332 lijima A, Tada R (1990) Evolution and Tertiary sedimentary basins of Japan in reference to opening of the Japan Sea. J Fac Sci Univ Tokyo Sec II 22: 121-171

Kawabe T (1996) The history of Lake Biwa. In "The Natural History of Lake Biwa, 2nd Edn." Ed by Research Group for Natural History of Lake Biwa, Yasaka Shobo, Tokyo, pp 25-72 (in Japanese)

Kawanabe H, Mizuno N, Hosoya K (2001) Freshwater Fishes of Japan, 3rd Edn. Yama-to-keikokusya, Tokyo, 720 pp (In Japanese)

Kitamura A, Takano O, Takata H, Omote H (2001) Late Plioceneearly Pleistocene paleoceanographic evolution of the Sea of Japan. Palaeogeogr Palaeoclimatol Palaeoecol 172: 81-98

KumazawaY, Yamaguchi M, Nishida M (1999) Mitochondrial molecular clocks and the origin of euteleostean biodiversity: Familial radiation of perciforms may have predated the Cretaceous/Tertiary boundary. In "The Biology of Biodiversity" Ed by M Kato, Springer-Verlag, Tokyo, pp 35-52

Orti G, Bell MA, Reimchen TE, Meyer A (1994) Global survey of mitochondrial DNA sequences in the threespine stickleback: evidence for recent migrations. Evolution 48: 608-622

Posada D, Crandall KA (1998) Modeltest: testing the model of DNA substitution. Bioinformatics 14: 817-818

Sakaizumi M (1984) Rigid isolation between the northern population and the southern population of the medaka, Oryzias latipes. Zool Sci 1: 795-800

Sorenson MD (1999) TreeRot, version 2. Boston University, Boston

Stevenson DE (2002) Systematics and distribution of fishes of the Asian goby genera Chaenogobius and Gymnogobius (Osteichthyes: Perciformes: Gobiidae), with the description of a new species. Species Diversity 7: 252-312

Swofford DL (2002) PAUP* Phylogenetic analysis using parsimony ( ${ }^{*}$ and other methods) version 4.0. Sinauer, Sunderland

Tada R (1994) Paleoceanographic evolution of the Japan Sea. Palaeogeogr Palaeoclimatol Palaeoecol 108: 487-508

Tamura K, Nei M (1993) Estimation of the number of nucleotide substitutions in the control region of mitochondrial DNA in humans and chimpanzees. Mol Biol Evol 10: 512-526

Yonekura N, Kaizuka S, Nogami M, Chinzei K (2001) Regional geomorphology of the Japanese Islands. Vol. 1. Introduction to Japanese Geomorphology. University of Tokyo Press, Tokyo

(Received June 8, 2004 / Accepted November 6, 2004) 